\title{
Fusões e Aquisições no Varejo Alimentar: uma análise das estratégias de entrada e de crescimento do Carrefour e Wal-Mart no mercado brasileiro
}

\author{
Roberto Minadeo ${ }^{1}$ \\ Marcos Antônio de Camargos ${ }^{2}$
}

\section{Resumo}

Em 2006, a Wal-Mart no Brasil ultrapassou o Carrefour, assumindo a segunda colocação no ranking do varejo alimentar do país. O maior varejista mundial ingressou no mercado brasileiro em 1995, enfrentou problemas em seus primeiros anos, porém, depois empreendeu um programa de crescimento pela abertura de novas lojas e pela aquisição de algumas redes nacionais. Enquanto isso, o Carrefour, que ingressara 20 anos antes na economia brasileira, e que atingira a liderança do ranking no ano de 1990, apenas por meio de um programa de abertura de novos hipermercados, iniciou um processo de ingresso no varejo de vizinhança, adquirindo diversas redes locais, porém, com resultados duvidosos. Logo após o anúncio da perda da segunda posição ao Wal-Mart, o Carrefour anunciou a compra da rede Atacadão, com a qual aspira retomar a liderança. Neste artigo faz-se uma análise das estratégias de entrada, da trajetória de crescimento das duas empresas, bem como da aquisição da rede Atacadão pelo Carrefour, considerada aqui como estratégica para a retomada da liderança no segmento e para defender-se da entrada ou afirmação dos seus concorrentes.

Palavras-chave: Estratégia de Entrada. Estratégia de Crescimento. Fusões e Aquisições. Varejo Alimentar. Carrefour. Wal-Mart.

\footnotetext{
${ }^{1}$ Doutor em Engenharia de Produção pela COPE-UFRJ. Professor e pesquisador do Programa de Mestrado em Administração da UNIEURO Endereço: Av. das Nações, Trecho 0, Conjunto 5, Brasilia-DF.E-mail: rminadeo@yahoo.com.

${ }^{2}$ Doutor em Administração pelo CEPEAD-UFMG. Professor e pesquisador do curso de Mestrado Acadêmico em Administração da Faculdade Novos Horizontes e das Faculdades IBMEC-MG. Endereço: Rua Alvarenga Peixoto, 1.270, sala C1 T05, B. Santo Agostinho-Belo Horizonte -MG -CEP:30.180-121. E-mail: marcos.camargos@unihorizontes. Artigo recebido em: 04/10/2008. Aceito em: 05/05/2009. Membro do Corpo Editorial Científico responsável pelo processo editorial: Thomas G. Brashear.
} 
Fusões e Aquisições no Varejo Alimentar: uma análise das estratégias de entrada e de crescimento do Carrefour e...

\section{Introdução}

A teoria do crescimento da firma preconizada por Penrose (1959) se alicerça, basicamente, na análise da dinâmica de mudança das oportunidades produtivas da firma ao longo da sua trajetória. Oportunidades estas, que podem ser exploradas mediante recursos específicos da empresa, denominados como valiosos, raros e difíceis de serem imitados, na condição de geradores de vantagem competitiva sustentável, ou seja, geradores de desempenho econômico acima do normal na indústria (BARNEY, 1991). Na visão de Penrose (1959) não são os recursos os inputs em si, mas sim os serviços que tais recursos podem fornecer; podendo, portanto, ser empregados de diferentes maneiras, cabendo aos gestores maximizar sua eficiência nas atividades produtivas.

Segundo Singh e Montgomery (1987), existem duas formas de uma empresa crescer:

a) crescimento interno: ou expansão por meio da construção de novas plantas e desenvolvendo mercados (greenfield investiment), que, por um lado, pode ser mais demorado e incorrer em maiores custos do que a aquisição de outra empresa, mas por outro, ser mais controlável, preservar a cultura organizacional e evitar várias outras dificuldades inerentes a um processo de F\&A; e

b) crescimento externo: por meio da fusão ou aquisição de outras empresas, o que proporciona por um lado crescimento rápido, entrada em novos mercados, minimização de barreiras de entrada, internacionalização entre muitos outros, mas que por outro lado pode resultar na destruição da riqueza dos acionistas devido a erros de avaliação provocados pelo excesso de confiança, prêmios pelo controle e custos de transação muito elevados, além de motivos fundamentados na teoria da agência, entre outros.

Sobre essa segunda estratégia, Pinto Júnior e lootty (2005) salientam que as empresas podem:

a) acessar novos mercados ou aumentar o poder de mercado de forma rápida;

b) obter ganhos de eficiência produtiva seja do ponto de vista estático ou dinâmico; 
c) diversificar suas atividades produtivas; $e$

d) alcançar a internacionalização de suas atividades, quando for o caso de uma operação cross-border.

Defendendo as alianças empresariais como modo de entrada em novos mercados, Rasmussen (1989) argumenta que as organizações não estariam vinculadas aos riscos dos investimentos iniciais (greenfield investment), pois a parceria levaria em conta certa experiência e know-how dos pares em processos a serem dinamizados. Para o autor, na nova realidade da economia internacional, as estratégias de parcerias são ferramentas fundamentais para uma empresa ou um grupo econômico entrar em mercados em um curto espaço de tempo, eliminando várias etapas que exigidas com a espera da maturidade de investimentos em novas unidades produtivas. Para Câmara (2007), as alianças corporativas criam oportunidades diversas para as empresas, porém as opções de expansão do negócio devem ser analisadas com cuidado, pois, dentre os riscos envolvidos, podem passar ao mercado a imagem de uma possível fragilidade financeira ou a tentativa de cartelização.

As fusões e aquisições (F\&As) podem ser entendidas como uma dentre as várias estratégias de crescimento e de internacionalização empresarial, além do licenciamento, investimento solo, alianças estratégicas, joint-ventures (SUEN; KIMURA, 1997). Lemes Jr., Rigo e Cherobim (2002) salientam que as F\&As podem ser vistas como estratégias de expansão e internacionalização de empresas, que podem alterar substancialmente o cenário no qual as empresas competem.

Os processos de F\&As são marcados por momentos de maior e menor intensidade no volume de operações (ondas), fortemente influenciados pelo desempenho e (des)valorização das ações nos mercados de capitais dos principais países da economia mundial. Trata-se de uma das atividades de destaque que reconfiguraram e transformaram a dinâmica das relações empresariais nas últimas duas décadas, quando então as denominadas quarta (anos 80) e quinta (anos 90) onda de F\&As criaram organizações com dimensões verdadeiramente globais. As F\&As são vistas pela teoria neoclássica como uma resposta visando aprimorar a eficiência no ambiente econômico: mediante políticas antitrustes e desregulamentação ou abertura de mercado (JOVANOVIC; ROUSSEAU, 2002), internacionalização, aumento da competição e maior integração dos mercados de capitais globais.

Pode-se dizer que a onda dos anos 90, de interesse direto neste artigo, visou basicamente o acesso a novos mercados, tecnologias e competências; 
maior poder econômico e de competição; sinergias e melhoria de eficiências administrativas e operacionais; diminuição do risco operacional e financeiro, além da proteção de mercado contra a entrada de concorrentes estrangeiros ou de aquisições indesejadas; ou a simples sobrevivência.

Inserida nesse cenário, ao longo das últimas décadas, a economia brasileira tem sofrido importantes alterações para se adequar a essa nova ordem produtiva e concorrencial, dentre as quais se destacam:

a) inserção na globalização financeira e produtiva (GONÇALVES et al., 1998);

b) abertura ao capital estrangeiro no início da década de 90;

c) implantação de políticas neoliberais, como o Plano Nacional de Desestatização (PND);

d) reorientação estratégica das suas empresas;

e) aumento dos processos de incorporação, fusão, aquisição e outras associações empresariais; $e$

f) aprimoramento no aparato regulatório e avanços nos mecanismos e no sistema de governança corporativa do país.

Em um primeiro momento, vários segmentos econômicos saíram da chancela estatal para a iniciativa privada por meio das privatizações. Numa etapa posterior, assistiu-se à transferência de grande parte do capital das empresas nacionais para o capital estrangeiro, mediante fusões e aquisições de empresas brasileiras (F\&As do tipo cross-border). Assiste-se, assim, à venda de empresas ou à transferência do seu controle para o capital estrangeiro e, consequentemente, a um aumento da profissionalização dos seus modelos de gestão, em substituição a um modelo familiar.

Em tese, o varejo ainda apresenta espaço para consolidação, pois segundo dados da consultoria KPMG (2006), de 1994 a 2006, houve apenas 157 processos de F\&As (supermercados e lojas varejistas juntos), o que representa $3,89 \%$ de um universo de 4.032 operações. O que é pouco se comparado com o segmento de maior número, o de alimentos, bebidas e fumo, no qual ocorreram 427 operações. Mas apesar disso, observa-se nos últimos anos um crescimento do número de F\&As; em especial, grupos nacionais sendo adquiridos por estrangeiros, com destaque para Wal-Mart e Carrefour. O ranking dos maiores supermercados brasileiros em 2006 teve a Wal-Mart na segunda posição, com $\mathrm{R} \$ 12,9$ bilhões em receitas, à frente do Carrefour, com $\mathrm{R} \$ 12,7$ bilhões. A Wal-Mart ingressou no Brasil em 1995, ou seja, em 
apenas 11 anos superou o Carrefour, que ingressara em 1975, e que já havia chegado à liderança do mercado, em 1990.

Neste artigo faz-se uma análise das estratégias de entrada, da trajetória de crescimento das duas empresas, bem como da aquisição da rede Atacadão pelo Carrefour, considerada estratégica para a retomada da liderança no segmento de defender-se dos concorrentes. $\mathrm{O}$ artigo tem a seguinte estrutura, após essa introdução, a Seção 2 apresenta os conceitos e teorias para o entendimento e análise das aquisições feitas pelas empresas. A Seção 3 trata da Metodologia. A Seção 4 apresenta breve evolução histórica do Carrefour e do seu maior concorrente - a rede Wal-Mart - primeiro em geral, e depois no mercado brasileiro. A Seção 5 faz uma análise da compra da rede Atacadão pelo Carrefour. A Seção 6 traz considerações finais, e, finalmente, as referências encerram o artigo.

\section{Fundamentos Teóricos}

\subsection{Estratégias de Entrada e de Crescimento}

Adam Smith (1996) em A Riqueza das Nações é considerado o precursor de estudos sobre um dos principais organismos econômicos, a firma, no que se denominou Teoria da Firma. Nesse enfoque, a firma passou de um mero mecanismo de condução da racionalidade que permeava a interação entre os agentes econômicos, tornando-se um agente de mudanças com um fim em si mesma, dotada de objetivos, peculiaridades e personalidade. Segundo Coase (1937), os fatores que induziram o crescimento do tamanho da firma foram:

a) menores custos de organização e baixo crescimento desses com um aumento nas transações organizadas;

b) menor probabilidade do empreendedor cometer erros e um pequeno aumento nos erros com crescimento das transações organizadas; $e$

c) redução no preço de fornecimento dos fatores de produção para firmas de portes maiores. Assim, o tamanho da firma era determinado pelos custos de transação e pelos custos e capacidade gerencial. 
No decorrer da sua trajetória, uma empresa passa por diferentes fases: crescimento, maturidade ou estabilidade e contração. A sobrevivência em cada uma delas é marcada pela capacidade dos seus gestores e da própria empresa em se adaptar às condições do ambiente de negócio. Os termos crescimento e desenvolvimento da firma foram definidos inicialmente por Starbuck (1965) como sendo a mudança em seu tamanho, quando este é medido pela quantidade de funcionários e a mudança na idade da organização, respectivamente, associando-os ao tamanho, possibilitando desde então a comparação entre organizações. No que se refere ao crescimento da firma, Vieira (2007) aponta as seguintes razões:

a) boas oportunidades de negócio;

b) forma de constituir barreiras à entrada de novos concorrentes ou criar mecanismos de defesa; $e$

c) interesse individual dos seus gestores.

Segundo Garcez (2006), as mudanças no ambiente de negócio, tanto em nível nacional, quanto internacional têm exigido a constante criação de vantagens competitivas em termos globais, seja pela inovação, qualidade ou mesmo liderança em custos - mediante ganhos de economias de escala advindas do crescimento. Assim sendo, o crescimento e o desenvolvimento de novos negócios, produtos, mercados e serviços surge como uma atividade essencial nas organizações como elemento de sustentação no longo-prazo. Para Starbuck (1965), o crescimento é consequência direta das decisões e estratégias implementadas pela firma. Mintzberg e Waters (1985) julgam ser praticamente impossível encontrar uma empresa que tenha uma trajetória de crescimento traçada essencialmente de forma deliberada, pois são vários os fatores (internos e externos) que interferem e determinam o seu crescimento.

O sucesso da expansão empresarial dependerá não só do empreendedorismo, ou da motivação pelo crescimento, mas também da competência da equipe gerencial que conduzirá os processos de crescimento. Ainda assim, o empreendedorismo, como um interesse pela expansão e pela busca de novos produtos ou novos mercados, pode criar as condições para que a competência seja criada ou trazida à firma (OLIVEIRA, 2006).

Almeida (2005) salienta que a internacionalização do varejo é relativamente recente, com exceção de algumas grandes empresas que foram pioneiras na expansão internacional. Segundo ele, até a década de 1990, a maior parte dos grandes varejistas confinou suas operações ao mercado doméstico 
ou manteve suas atividades internacionais em plano secundário, restringindo-se a mercados próximos, geográfica e culturalmente. O autor aduz que na década de 1990 as mudanças ambientais, como integração regional, expansão internacional das indústrias fornecedoras e emergência de segmentos de consumidores globais foram responsáveis por alterar esse quadro e exigir dos grandes varejistas uma nova estratégia.

A estratégia de entrada em novos mercados (internacionais) deve ser executada de maneira planejada, visto que sempre envolve, além de dificuldades operacionais, incerteza, riscos e complexidade. Segundo Almeida (2005), esses três últimos entraves se originam:

a) da necessidade de operar em ambientes distintos do mercado doméstico, o que pode envolver sistemas políticos, sociais e econômicos e marco legal com características bastante diferenciadas, costumes exóticos e práticas de negócios pouco familiares (incertezas);

b) da própria incerteza ambiental e do fato de a empresa necessitar comprometer recursos materiais, financeiros e gerenciais (riscos); $e$

c) do grande número de operações envolvidas na transposição de fronteiras nacionais, gerando novas necessidades de controle (complexidade).

Visando expandir de maneira coordenada, uma empresa deve selecionar uma estratégia de crescimento que resulte em última instância no aumento do ser valor (criação de valor). O crescimento pode ser atingido de várias maneiras:

a) crescimento interno: é obtido pelo aumento das vendas, da capacidade de produção e da força de trabalho;

b) fusões e aquisições: por meio das quais o crescimento pode ocorrer por meio de uma integração horizontal, vertical ou mediante diversificação, denominada de criação de conglomerados; $e$

c) joint-ventures: tipo de associação entre empresas na qual a participação e a gestão são compartilhadas pelos parceiros.

Além dessas modalidades, é possível citar o licenciamento, private equity, venture capital, entre outras, não pertinentes a este estudo.

O enfoque competitivo passa a ser o balanceamento entre o crescimento dos negócios atrativos vigentes e o desenvolvimento de novos negócios, 
visando à diversificação de riscos, e se contrapondo à obsolescência tecnológica e à regulação, em função de fatores como:

a) efeitos do aumento da concorrência, da saturação de oferta $e$ maturação das indústrias;

b) da rápida difusão de novas tecnologias; $e$

c) da regulação antitruste (GARCEZ, 2006).

\subsection{Conceitos e Diferenciação de Fusão, Consolidação e Aquisição}

Uma fusão ou consolidação é um dos métodos pelo qual uma empresa pode adquirir outra. Além da fusão, a aquisição pode ser feita por meio da compra de ações ou ativos. O pagamento pode ser em dinheiro, ações ou outros títulos, com o processo sendo realizado via bolsa de valores, por meio de uma oferta privada de aquisição da administração da empresa adquirente à administração ou ao conselho de administração da empresa-alvo, denominada também de tomada amigável de controle acionário; ou mediante uma oferta pública de aquisição (tender offer) feita pela firma adquirente diretamente aos acionistas da empresa-alvo, em uma oferta para comprar um determinado número de ações a um preço específico em uma data estipulada. Situação também chamada de tomada hostil de controle acionário.

Entretanto, existem algumas distinções básicas entre fusão ou consolidação e aquisição:

a) em uma fusão, pode haver a criação de uma nova firma (consolidação), enquanto na aquisição, uma das empresas envolvidas mantém suas identidades jurídicas;

b) na fusão, geralmente a forma de pagamento utilizada é uma permuta de ações, enquanto, na aquisição, a forma de pagamento pode ser dinheiro, ações, ou outros títulos; $e$

c) na fusão, as firmas geralmente são do mesmo setor, têm a mesma atividade-fim, enquanto, nas aquisições, é comum as firmas serem de setores diferentes. 


\subsection{Classificação das Fusões e Aquisições}

Levando-se em consideração a dimensão "relacionamento" entre as empresas envolvidas, conforme Chatterjee (1986), uma F\&A pode ser classificada em:

a) relacionadas, que envolvem empresas que competem em termos de produtos, mercados ou tecnologia; $e$

b) não-relacionadas, que ao contrário, envolvem empresas entre as quais não há competição.

Considerando fatores econômicos, uma F\&A pode ser classificada em:

\begin{tabular}{|l|l|l|}
\hline \multicolumn{1}{|c|}{ Classificação } & \multicolumn{1}{|c|}{ Definição } & \multicolumn{1}{c|}{$\begin{array}{c}\text { Vantagem/Fontes de } \\
\text { Sinergias }\end{array}$} \\
\hline Horizontal & $\begin{array}{l}\text { União entre firmas atuantes no } \\
\text { mesmo ramo de atividade, } \\
\text { geralmente concorrentes }\end{array}$ & $\begin{array}{l}\text { a) aumento da participação de } \\
\text { mercado e do poder de } \\
\text { barganha; e b) redução de } \\
\text { custos operacionais (economi- } \\
\text { as de escala) }\end{array}$ \\
\hline Vertical & $\begin{array}{l}\text { Quando resulta da união entre } \\
\text { firmas que fazem parte da } \\
\text { mesma cadeia produtiva, } \\
\text { podendo ser para cima (mon- } \\
\text { ante), em direção aos fornece- } \\
\text { dores; ou para baixo (jusante), } \\
\text { em direção aos distribuidores }\end{array}$ & $\begin{array}{l}\text { a) eliminação de processos } \\
\text { produtivos, redução de custos } \\
\text { indiretos e de coordenação das } \\
\text { atividades de distribuição com } \\
\text { o objetivo de incremento de } \\
\text { sinergias; b) economias de } \\
\text { cadeia vertical/escopo horizon- } \\
\text { tal; e c) melhorias ou inova- } \\
\text { ções que podem ser } \\
\text { transferidas ou partilhadas } \\
\text { entre as unidades de negócio }\end{array}$ \\
& $\begin{array}{l}\text { a) diversificação leva à redu- } \\
\text { ção dos riscos, além de } \\
\text { possibilitar um melhor aprovei- } \\
\text { tamento de oportunidades de } \\
\text { investimento }\end{array}$ \\
\hline Conglomerado & $\begin{array}{l}\text { Quando envolve firmas em } \\
\text { amos de atividade não } \\
\text { elacionados, cujo principal } \\
\text { bjjetivo é a diversificação de } \\
\text { nvestimentos }\end{array}$ \\
\hline
\end{tabular}

Quadro 1: Classificação dos Processos de Fusões e Aquisições.

Fonte: Ross, Westerfield e Jaffe (2002); Weston e Brigham (2000); Wright, Kroll e Parnell (2000). 
Dependendo da abordagem e da forma com que a negociação de um processo de F\&A é conduzida, ela pode ser amigável/consensual (friendly takeover) ou hostil (hostile takeover). As amigáveis podem ser definidas como uma mudança na propriedade corporativa, sem uma mudança acompanhante no controle administrativo. Já as hostis podem ser definidas como uma operação de tomada de controle não solicitado, que resulta na substituição da administração da firma adquirida (HIRSCHEY, 1986).

Dependendo da nacionalidade das empresas envolvidas, elas podem ser classificadas em:

a) domésticas, quando envolve empresas originárias do país na qual ocorreram; $e$

b) cross-border, quando envolve uma ou mais empresas que têm sedes em países diferentes.

E dependendo da motivação e do destino das empresas pós-F\&A, elas podem ser classificadas em:

a) operacional ou estratégica, quando as operações de duas ou mais empresas são integradas com a expectativa de se obter sinergias, melhorias operacionais e gerenciais e acesso a novos mercados; $e$

b) financeira, quando as empresas combinadas não serão operadas como uma unidade única e a partir da qual nenhuma economia operacional significativa seja esperada. Os adquirentes estão em buscas de retornos financeiros rápidos e vendem a empresa adquirida em sua totalidade ou de maneira fracionada (ativos estratégicos), pouco tempo depois.

\subsection{Sinergias Esperadas Fusões e Aquisições}

Decorrentes diretas dos motivos por trás de uma união empresarial, as sinergias são comumente esperadas nas transações de F\&A. Elas representam os ganhos e benefícios decorrentes da união empresarial. Lemes Jr., Rigo e Cherobim (2002) apresentam, no Quadro 2, as fontes de sinergias em F\&As: 


\begin{tabular}{|l|l|}
\hline \multicolumn{1}{|c|}{ Sinergias } & \multicolumn{1}{c|}{ Fonte(s) } \\
\hline $\begin{array}{l}\text { Economias de } \\
\text { escalas } \\
\text { operacionais }\end{array}$ & $\begin{array}{l}\text { Redução/eliminação de custos e despesas com atividades } \\
\text { corporativas (marketing, finanças, etc.) }\end{array}$ \\
\hline $\begin{array}{l}\text { Economias } \\
\text { financeiras }\end{array}$ & $\begin{array}{l}\text { Melhor estrutura de capital, maior capacidade de alavancagem } \\
\text { com menores custos de endividamento }\end{array}$ \\
\hline $\begin{array}{l}\text { Melhorias na } \\
\text { eficiência } \\
\text { gerencial }\end{array}$ & $\begin{array}{l}\text { Substituição de administração ineficiente, geralmente da } \\
\text { empresa adquirida, melhorando assim o seu desempenho } \\
\text { econômico e financeiro }\end{array}$ \\
\hline $\begin{array}{l}\text { Poder de } \\
\text { monopólio }\end{array}$ & $\begin{array}{l}\text { Maior porte da empresa resulta em um maior poder de merca- } \\
\text { do, de negociação e de competição }\end{array}$ \\
\hline Economias fiscais & $\begin{array}{l}\text { Utilização de isenções e compensações autorizadas pela lei, } \\
\text { como é o caso do uso de prejuízos fiscais decorrentes de prejuí- } \\
\text { zos operacionais, de um planejamento tributário ou da elimina- } \\
\text { ção de bitributação }\end{array}$ \\
\hline
\end{tabular}

Quadro 2: Fontes de sinergias em F\&As.

Fonte: Compilado de Lemes Jr., Rigo e Cherobim (2002).

\subsection{Motivos e Dificuldades nos Processos de Fusões ou Aquisições}

Segundo Andrade, Mitchell e Stafford (2001), a teoria econômica apresenta as seguintes razões para a ocorrência das F\&AS:

a) ferramenta estratégica para o crescimento e sucesso da empresa, baseada nas possíveis economias de escala, sinergias e a maior eficiência na gestão de ativos;

b) tentativa de criar poder de mercado, pela formação de monopólios ou oligopólios;

c) disciplina do mercado, como nos causa da substituição de gestores incompetentes de companhias adquiridas;

d) comportamento discricionário de gestores de empresas adquirentes, que se engajam em tais processos visando o benefício próprio, como o aumento do tamanho da empresa e outros aspectos da teoria da agência; $e$ 
e) tirar vantagem de oportunidades de diversificação, pela exploração de mercado de capitais.

Independente de qual seja a motivação de uma F\&A, ela não deve ser vista como uma simples estratégia para uma empresa crescer rapidamente, mas como um processo complexo, que exige um grande planejamento e uma adequada implementação. Dentre as suas principais dificuldades destacamse: choques de culturas corporativas; divergências e incompatibilidades de estilos de gestão; conflitos e batalhas políticas pelo poder; dificuldade de entendimento, pela firma adquirente, das rotinas e capacitações da empresa adquirida; saída de pessoas estratégicas; recursos para viabilizar o negócio; perda de foco e de direção; fofocas e boatos internos; desmotivação dos funcionários diante do risco de dispensa, pois essas operações geralmente são sinônimas de eliminação de departamentos e downsizing; inexistência de objetivos; falta de visão do negócio e dos problemas futuros da nova empresa; estrutura organizacional, publicidade, imagem e relacionamento com fornecedores e clientes.

\section{Aspectos Metodológicos}

Esta pesquisa pode ser classificada como descritiva e conduzida por um enfoque qualitativo, visto que, teve como objetivos: contextualizar, descrever e analisar a estratégia de entrada e a trajetória de crescimento de duas empresas líderes mundiais no segmento varejista, além da análise de uma das maiores aquisições nesse segmento, ocorrida no mercado brasileiro, visando entender melhor os seus possíveis desdobramentos para os seus diversos stakeholders e para a economia brasileira.

Quanto ao método, trata-se de um estudo de caso. Martins (2006, p. 1-5) aponta que um estudo de caso deve ser:

a) importante, por apresentar um engenhoso recorte de uma situação complexa da vida real;

b) eficaz, por enunciar com detalhes o protocolo que orientou o estudo; $e$

c) suficiente, pelo fato de as fronteiras entre o fenômeno em estudo e o seu contexto estarem claramente delimitadas, evitando interpretações e descrições indevidas ou não contempladas pelo estudo. 
Quanto ao método, a pesquisa também foi histórica - com o recorte de apontar as aquisições ocorridas na trajetória dos grupos envolvidos, procurando situá-las em seus respectivos processos de crescimento. Segundo Lakatos e Marconi (1991), o método histórico pressupõe que as instituições se originam no passado, sendo importante pesquisar suas raízes, para compreender sua natureza e função. Esse método consiste em investigar acontecimentos, processos e instituições do passado para verificar a sua influência no presente.

A pesquisa documental teve como principais fontes de informação:

a) Legislação brasileira (CADE, Lei n 8.884/94, Lei n ${ }^{\circ} 6.404 / 76$ e Lei $\left.n^{\circ} 10.303 / 01\right)$ : informações sobre os aspectos antitrustes, legais e societários e que vigoram na economia brasileira;

b) Imprensa especializada (Gazeta Mercantil, Valor Econômico e Jornal Folha de São Paulo) ${ }^{3}$, informações e dados sobre a aquisição; $e$

c) Banco de dados de fusões e aquisições nacionais dos autores.

Resumidamente, pode-se dizer que a pesquisa foi elaborada da seguinte forma: com base na teoria sobre as F\&As da literatura econômico-financeira e estratégica, procedeu-se a uma análise das aquisições da Wal-Mart e do Carrefour no Brasil, a partir de dados econômicos, estratégicos e mercadológicos.

\section{Breve Histórico da Wal-Mart e do Carrefour}

\subsection{Wal-Mart}

Costa (2005) aponta que Sam Walton ingressou no varejo como franqueado de uma rede, logo após a II Guerra. No ano de 1962, criou a WalMart, que chegou ao ano de 1970 a 32 lojas, porém, com 78 sócios diversos e um elevado endividamento da família. Em outubro de 1970 houve uma abertura do capital, com a captação de US\$ 4,95 milhões junto a 800 investidores, na qual a família manteve $61 \%$ das ações, porém, liquidou as dívidas.

\footnotetext{
${ }^{3}$ Por se tratar de um estudo de trajetória empresarial, foram utilizados vários artigos desses jornais, em anos diferenciados, motivo pelo qual se eximiu de colocar o ano.
} 
Walton e Huey (1993) afirmam que a Wal-Mart começou a distribuir lucros aos gerentes em 1970 e a todos os funcionários já no ano seguinte lançando as bases de um relacionamento com seus recursos humanos que pode ser considerado um tipo de aliança, o qual foi importante fator para o bom atendimento e o baixo índice de roubos nas lojas. Por exemplo, Georgia Sanders trabalhou na empresa de 1968 a 1989, no departamento de aparelhos eletrônicos, e recebeu US $\$ 200$ mil em participação nos lucros ao se aposentar. Em 1980, a empresa começou a dividir com os funcionários qualquer diminuição dos furtos nas lojas - um velho problema do varejo. Segundo Ghemawat (2000), nos anos 80, a rede começou a testar vários novos formatos além da loja original: abriu os três primeiros Sam's Club em 1983, e, pouco depois, a primeira deep discount drugstore e uma loja Helen's Arts and Crafts. As três lojas Helen's foram vendidas em 1988, e as drogarias em 1990.

Segundo Costa (2006), em sua estratégia de expansão, a Wal-Mart utilizou tanto o crescimento orgânico quanto a compra de outras redes de lojas. Em 1983, a Wal-Mart é pioneira na introdução de scanners para leitura ótica no ponto de venda. O autor aduz que, após uma reunião de dois dias entre os dez principais dirigentes da Wal-Mart com os da Procter \& Gamble, em 1987, esta empresa passou a suprir diretamente as lojas da rede e a controlar os estoques de fraldas, sem a necessidade de pedidos. No primeiro ano em que a Wal-Mart e a Procter \& Gamble fizeram uma aliança, as vendas naquele ponto de distribuição cresceram 40\% (CHRISTOPHER, 1995). Essa aliança foi ampliada, tornando-se um verdadeiro padrão no relacionamento varejo-indústria.

Em 1990, assumiu a posição de maior grupo varejista dos EUA. Costa (2006) afirma que após o falecimento de Sam Walton em 1992, a empresa somava 371 mil funcionários e quase duas mil lojas. A presidência passou para David Glass, que vinha sendo preparado pelo próprio Walton, e que já recebera o posto de CEO quatro anos antes. Glass ingressara na empresa em 1976 , tendo ajudado a desenvolver a logística. A sucessão teve nova etapa no ano 2000, quando Lee Scott assumiu a Presidência. Rocha e Dib (2002) apontam que em 1999 a rede contava com 2.884 lojas, 910 mil funcionários, receitas de US\$ 137 bilhões - sendo US\$ 12 bilhões gerados fora dos EUA.

Segundo Costa (2005), em seu processo de crescimento internacional, a Wal-Mart construiu lojas próprias, associou-se a companhias locais e com- 
prou redes concorrentes. O autor aduz que em 2004, apenas uma fatia de $13,3 \%$ de sua receita vinha de países de fora de sua proveniência original, contra os 31,1\% do Carrefour. Rocha e Dib (2002) afirmam que o ingresso da Wal-Mart em outros países causou grandes reações, por exemplo, na GrãBretanha o valor das ações das maiores varejistas em bolsa de valores sofreu uma redução.

Em 1995, a Wal-Mart ingressou no Brasil, em associação com a Lojas Americanas. Rocha e Dib (2002) afirmam que o próprio Sam Walton possuía um longo relacionamento com Jorge Lemann - importante acionista da Lojas Americanas. Ainda apontam que o ingresso da Wal-Mart no Brasil foi comparado ao do Carrefour - na medida em que ambos provocaram mudanças estruturais no setor, classificando essas reações em quatro categorias: ações de neutralizar a concorrência, criação de vantagens competitivas, redefinição de mercados e mudanças de controle acionário.

A rede seguiu o mesmo padrão de ingresso no México, em 1991, que fora a sua primeira expansão internacional, e onde também se associara a um varejista local, e passara a seguir um processo de crescimento padrão greenfield. Porém, tanto nesse mercado, quanto no Brasil, em poucos anos, a Wal-Mart adquiriu as ações do sócio local, passando a deter a totalidade do negócio. Assim, em 1997, a Lojas Americanas vendeu seus 40\% da operação brasileira da Wal-Mart. Essa associação permitira o ingresso da Wal-Mart no Brasil. Em contrapartida, segundo Heitmann (2002), a Wal-Mart repassou a Lojas Americanas know-how sobre centros de distribuição, que permitiu à rede brasileira implantar suas três primeiras unidades, e a partir de então, apresentar consideráveis melhorias em seus resultados operacionais $e$ financeiros.

Porém, no processo de ingresso em outros países, a Wal-Mart passou a implementar políticas de aquisições de redes já existentes, como foi o caso de Alemanha e Grã-Bretanha. Portanto, aqueles anos de aprendizado, como uma rede relativamente pequena no mercado brasileiro, foram abreviados no ingresso nesses países, e, curiosamente, a rede vendeu suas operações no mercado alemão em 2006, onde não estava obtendo formas eficientes de concorrer com as redes de descontos locais - notadamente a Aldi.

Costa (2005) afirma ainda, que em 2004, a Wal-Mart detinha 3.460 lojas de desconto, 1.729 supercenters, 618 Sam's Club e cem lojas de vizinhança. Fox (2005) afirma que a Wal-Mart é o maior empregador do mundo, com cerca de 1,3 milhões de funcionários, sendo um milhão nos EUA. Aponta 
que os economistas cunharam a expressão "efeito Wal-Mart" para se referir ao fato de que a empresa, por meio de seus ganhos de produtividade, ajudou a eliminar a inflação. A rede é líder de mercado em: vestuário: roupas de cama, joias, artigos de mercearia e brinquedos. Além disso, é o maior varejista mundial de músicas - com $20 \%$ do mercado de músicas gravadas dos EUA e, aproximadamente, $14 \%$ do mercado mundial. O autor aponta que especificamente no varejo de música, perto de 1.200 lojas encerraram as atividades nos EUA entre 2003 e 2004 - sendo que parte disso pode ser devido à concorrência da Wal-Mart.

Silverstein e Fiske (2003, p. 38) chegam a apontar os ganhos de eficiência do varejo como um dos motivos do crescimento do mercado do luxo:

[...] ao longo dos anos, custos reduzidos e margens comprimidas de varejistas como Wal-Mart, Costco, Home Depot, Lowe's, Kohl's e Circuit City permitiram ao público contar com preço baixo todo dia em vários artigos $e$, portanto, baixar o custo de vida. Estimamos que em 2001 ao menos US\$ 70 bilhões tenham se tornado disponíveis dessa forma para o consumo no novo-luxo.

\section{I.I. Wal-Mart Brasil}

O ingresso da rede Wal-Mart no Brasil ocorreu em 1995, por meio de uma joint-venture com a Lojas Americanas, que detinha $40 \%$ das ações. Ou seja, utilizou-se de uma parceria estratégica com uma empresa brasileira para ingressar neste mercado. Para a Wal-Mart, essa parceria representou uma garantia contra o risco político por se tratar de mais um varejista, de bandeira estrangeira. Para a empresa brasileira essa parceria trouxe tecnologia e knowhow necessários para a criação do seu centro de distribuição, fundamentais para que a rede passasse a ter um novo padrão de gestão e, por conseguinte, um novo patamar de resultados.

Inicialmente, a estratégia adotada pela Wal-Mart foi o crescimento orgânico, chegando ao final dos seus dez anos de atuação no mercado brasileiro a somar 24 lojas (COSTA, 2005). Com a compra do Bompreço, a empresa passou a 163 lojas e seu faturamento anual subiu de $R \$ 1,7$ bilhão para $R \$ 5$ bilhões. Cabe destacar que na sua trajetória, a rede Bompreço realizara di- 
versas aquisições. Essa rede pertencia ao grupo holandês Royal Ahold, que em meio a uma crise na controladora teve que desfazer inúmeros ativos internacionais que vinha construindo em um acelerado processo de crescimento. Para a Wal-Mart, os problemas da Royal Ahold representaram uma extraordinária oportunidade, visto que, no Brasil o grupo holandês havia adquirido várias redes familiares e iniciado um processo de consolidação $e$ profissionalização. Desse modo, a Wal-Mart poupou anos que gastaria para construir essa rede, e não pagou um preço elevado devido à problemática situação do grupo holandês, penetrando assim, nos estados do nordeste brasileiro em privilegiada situação.

O Quadro 3 apresenta as aquisições da Wal-Mart no Brasil.

\begin{tabular}{|l|l|}
\hline \multicolumn{1}{|c|}{ Data } & \multicolumn{1}{c|}{ Aquisição } \\
\hline 2004 & $\begin{array}{l}\text { Rede Bompreço, 118 lojas, sendo 28 hipermercados, 87 super- } \\
\text { mercados, 93 farmácias e três magazines }\end{array}$ \\
\hline 2005 & $\begin{array}{l}\text { Ativos da Sonae no Brasil, com 140 lojas das bandeiras BIG, } \\
\text { Nacional, Mercadorama e Maxxi, nos estados do Rio Grande do } \\
\text { Sul, Paraná, Santa Catarina e São Paulo }\end{array}$ \\
\hline
\end{tabular}

Quadro 3: Aquisições da Wal-Mart no Brasil.

Fonte: Banco de dados próprio.

Com a compra dos ativos do grupo Sonae, pertencente a empresários portugueses, em termos de supermercados no Brasil, a Wal-Mart passou a contar com 295 lojas em 17 estados, ampliando de modo significativo a sua presença nas regiões Sudeste e Sul. Ou seja, ampliou sua atuação para as duas regiões mais importantes economicamente da economia brasileira. $\mathrm{O}$ grupo Sonae fizera inúmeras aquisições no país e estava enfrentando dificuldades na integração desses ativos. Além disso, seus ativos no varejo em Portugal eram uma associação com a francesa Promodès - que estava sendo encerrada, pois se fundira com o Carrefour. Assim, a Wal-Mart pôde adquirir de uma só vez um conjunto respeitável de lojas e aplicar sua experiência de gestão no varejo e de assimilação de outras redes adquiridas.

O paralelo que pode ser traçado entre essas aquisições da Wal-Mart é que também o grupo português Sonae havia adquirido diversas redes de lojas familiares e iniciado o processo de profissionalização. Fato que proporcionou à Wal-Mart, além da ampliação estratégica da sua atuação para as regiões Sul e Sudeste, a eliminação de várias etapas no seu processo de cres- 
cimento empresarial, e, novamente, sem pagar um preço elevado em função dos resultados obtidos no Brasil e da indisponibilidade de realizar novos investimentos, que se faziam necessários para consolidar as aquisições realizadas. Finalmente, a aquisição dos ativos da Sonae supôs duas importantes inovações:

a) um dos ativos do Sonae - o Maxxi Atacado - representou o ingresso no setor informalmente denominado "atacarejo" - o mesmo da rede Atacadão, que veio a ser comprada pelo Carrefour; esse formato mescla as características do atacado de autosserviço com as do hipermercado. Apesar de se intitularem atacadistas, essas lojas visam o público formado pelas pessoas físicas; $e$

b) outro ativo adquirido, a rede Mercadorama, já estava realizando vendas pela Internet, em Curitiba, representando, portanto, o ingresso da Wal-Mart no comércio eletrônico no Brasil.

Em 2006, a Wal-Mart abriu 14 lojas, ou seja, continuou mesclando uma estratégia de crescimento marcada por aquisições bem assimiladas, ao lado do crescimento interno. A Wal-Mart encerrou o ano de 2006 com 304 lojas no Brasil, com seu faturamento crescendo de $R \$ 11,7$ bilhões para $R \$ 12,9$ bilhões.

Assim, pode-se perceber que as operações de aquisições tiveram importante papel na estratégia de crescimento da Wal-Mart no Brasil - ao lado do crescimento orgânico. Enquanto no Brasil superava o Carrefour e assumia a segunda posição no varejo, nesse mesmo ano, a Wal-Mart reassumiu a liderança global em receitas, com seus US $\$ 351,1$ bilhões, contra os US \$347,3 bilhões da ExxonMobil. Essa liderança fora mantida entre os anos 2000 e 2004, e perdida em 2005 em função da forte elevação dos preços do petróleo.

\subsection{Carrefour}

O Carrefour criou seu primeiro hipermercado em 1963, sendo que Wortmann (2004, p. 431) afirma ter sido um pioneirismo europeu. Em 1970, abriu seu capital e três anos depois fez sua primeira expansão internacional ingressando na Espanha. Seu crescimento, tanto na França quanto no exterior, foi mediante a abertura de lojas próprias, durante as suas primeiras décadas. Burt, Dawson e Sparks (2003) afirmam que nos anos 70, os hipermercados do Carrefour não foram bem-sucedidos na Grã-Bretanha - 
em função de regulamentações para defender os varejistas locais. Na década seguinte, a rede fracassou nos EUA com seu modelo de hipermercado. Além disso, os autores afirmam, ainda, que a rede tentou sem sucesso vários formatos na Grã-Bretanha.

Apenas em 1991 realizou uma aquisição de porte: a também francesa Euromarchè. A partir de então, diversas outras aquisições foram realizadas tanto na França quanto no exterior. Em 1976, o Carrefour introduziu produtos sem marca, porém, com preços mais baixos, e lançou produtos com sua própria marca em 1985. A partir de 1991, passou a oferecer pacotes turísticos em suas lojas.

Segundo Rocha e Dib (2002), o Carrefour teve US\$ 80 milhões em prejuízos nos EUA, encerrando as operações em 1993 - porém, mantendo uma participação acionária na Costco e na Office Bureau. Os autores apontam que a rede ingressou no México por meio de uma joint-venture com o grupo Gigante - o segundo maior varejista local - abrindo um confronto direto com a Wal-Mart. Ainda aduzem que a rede somou receitas de US $\$ 28$ bilhões em 1994 - valor que subiu a US\$ 37 bilhões em 1999. Neste último ano, a empresa contava com 240 mil funcionários e 8.791 lojas em 21 países, com vários formatos diferentes. O total de lojas fora da França era de 494 unidades.

Rocha e Dib (2002) e Colla (2004) afirmam que o Carrefour se fundiu ao Promodès em 1999 como uma reação ao ingresso da Wal-Mart no mercado europeu. O Promodès inaugurara sua primeira loja no ano de 1961; havia lançado a marca Champion no ano de 1969, e a marca Continent para hipermercados no ano de 1972. Dawson (2001, p. 255) afirma que em 1990 o Promodès contava com 2.738 lojas, valor que subiu para 4.711 no ano de 1998. Além disso, neste último ano, a rede atuava em 12 países. Finalmente, aponta que as receitas do grupo subiram de US\$10,56 bilhões em 1990 para US\$22,89 bilhões em 1998. Nesse mesmo período, as receitas do Carrefour, segundo o autor, passaram de US $\$ 13,67$ bilhões para US $\$ 37,79$ bilhões; a rede de lojas passou de 369 para 1.661 unidades, atuando em 20 países no ano de 1998.

\subsubsection{Carrefour Brasil}

Dupont (1991, p. 78-79) conta que a agência de propaganda brasileira Norton abriu um escritório em Paris, em 1973, dentro de um acordo 
operacional com uma agência francesa, com o intuito de atrair negócios ao país. O audiovisual "Brasil, Uma Realidade Mundial" foi apresentado a mais de 150 empresários europeus. Fruto desse trabalho foi o contato com o Carrefour, que ingressou no país em 1975, ficando com a Norton sua conta durante 11 anos. O Brasil foi o primeiro país em que o Carrefour investiu fora da Europa.

Um estudo da ABRAS - Associação Brasileira de Supermercados (1993) aponta que a chegada do Carrefour no Brasil foi um verdadeiro divisor de águas, sendo seu modelo adotado por outras empresas do ramo, tendo, porém, esbarrado na mentalidade centralizadora do empresariado local - que viria a se reestruturar a partir do final dos anos 80 . O mesmo estudo afirma que cada hipermercado da rede é uma unidade autônoma que seleciona seu sortimento, compra e controla o estoque, conforme sua área de influência. Ainda segundo esse estudo mostra que quando a rede somava 13 mil funcionários, apenas três eram franceses - indicando um elevado grau de absorção de integração do grupo à cultura local.

Minadeo (s/d) aponta que o Carrefour cresceu e se consolidou no país pela criação de uma rede de hipermercados, chegando à liderança do varejo alimentar nacional no ano de 1990. Porém, a partir da segunda metade dos anos 90, essa estratégia se mostrou limitada para sua expansão no país. Assim, por um lado, o Carrefour ingressou no formato de lojas menores de vizinhança por meio de aquisições. Por outro lado, algumas das redes adquiridas dispunham também de alguns hipermercados.

Segundo Rocha e Dib (2002), o Carrefour investiu US\$ 217 milhões em 1995, dos quais US\$ 81 milhões foram aplicados na abertura de novas lojas. Com mais seis lojas abertas no ano seguinte, a rede chegou a um total de 44 lojas. Os autores afirmam que as operações brasileiras do Carrefour em 1999 apresentaram receitas em torno de US\$ 4,3 bilhões, com mais de 28 mil funcionários, apresentando o maior índice de vendas por empregado do setor, e o segundo maior índice de vendas por check-out, isto é, um balcão com uma caixa registradora, ou qualquer outro equipamento que permita a soma e a conferência das compras. Ainda apontam que nesse mesmo ano o Carrefour adquiriu as 23 lojas do formato supermercados que eram da rede Lojas Americanas.

O Quadro 4 apresenta as aquisições do Carrefour no Brasil. 


\begin{tabular}{|c|c|}
\hline Data & Aquisição \\
\hline 1997 & $\begin{array}{l}50 \% \text { das ações ordinárias do Eldorado S.A. Com., Ind. e Import., rede de } \\
\text { hipermercados com } 8 \text { lojas no estado de São Paulo. Dois anos depois, } \\
\text { adquiriu os } 50 \% \text { restantes }\end{array}$ \\
\hline 1998 & $\begin{array}{l}\text { Adquiriu a rede francesa Comptoirs Modernes, que estava presente no Brasil } \\
\text { pela recente compra dos } 23 \text { supermercados da rede Lojas Americanas }\end{array}$ \\
\hline 1999 & $\begin{array}{l}\text { Rede Planaltão, líder no Centro-Oeste, com receitas de } \mathrm{R} \$ 174 \text { milhões no } \\
\text { ano anterior, e uma rede de } 16 \text { lojas mais uma central de cestas básicas }\end{array}$ \\
\hline 1999 & Adquiriu um hipermercado em Manaus, o Hiper Manaus, da família Gonçalves \\
\hline 1999 & $\begin{array}{l}\text { Unibrás Alimentos, com } 14 \text { supermercados entre o Espírito Santo e o Rio de } \\
\text { Janeiro }\end{array}$ \\
\hline 1999 & Rede Rainha, com 15 lojas no Rio de Janeiro \\
\hline 1999 & $\begin{array}{l}\text { Rede Continente, com } 13 \text { lojas, também no Rio de Janeiro, das quais três } \\
\text { eram hipermercados }\end{array}$ \\
\hline 1999 & Rede Dallas, com 11 lojas também no Rio, sendo dois hipermercados \\
\hline 1999 & Comercial Matheus Vinhedo Ltda., de Vinhedo, SP \\
\hline 1999 & Rede Mineirão, uma das maiores de Minas Gerais \\
\hline 2000 & Adquiriu o supermercado Big Bom, de Indaiatuba, interior paulista \\
\hline 2000 & Rede Antonelli, do Estado de São Paulo \\
\hline 2005 & $\begin{array}{l}\text { Dez hipermercados do grupo português Sonae no Estado de São Paulo, } \\
\text { atuantes com a bandeira Big }\end{array}$ \\
\hline 2005 & Uma loja da rede Mercantil São José, em Fortaleza, Ceará \\
\hline 2007 & Rede Atacadão \\
\hline
\end{tabular}

Quadro 4: Aquisições Realizadas na Trajetória do Carrefour.

Fonte: Banco de dados próprio.

A rede Carrefour ingressou no Brasil em 1975, e, no ano de 1980, detinha a décima colocação no ranking do varejo alimentar. Por meio do seu processo de crescimento interno, pela abertura de novos hipermercados, galgou uma posição ao ano e chegou em 1990 como a líder do setor - posição mantida até o ano 2000. Ou seja, percebe-se que essa trajetória de sucesso não teve qualquer apoio em operações de F\&As. No entanto, a rede prosseguiu sua trajetória realizando algumas aquisições de hipermercados, porém, em especial, de supermercados ou lojas de vizinhança. Percebe-se que a rede 
empreendeu inúmeras aquisições desse último formato de loja, visando deixar de ser apenas uma rede de hipermercados.

Algumas aquisições do Carrefour foram problemáticas. Diversas lojas foram fechadas ou vendidas - por vezes até aos seus antigos donos. Algumas das lojas adquiridas receberam novas bandeiras, passando a apresentar, em vários casos, um padrão de receitas inferior ao que apresentavam antes da aquisição. Desse modo, pode-se afirmar que o Carrefour não apresentou no seu crescimento via aquisições o mesmo padrão de sucesso que tivera na sua meteórica ascensão dos anos 80, via crescimento orgânico, pela abertura de novos hipermercados. A rede empreendeu dois passos: no primeiro promoveu inúmeras aquisições, e no segundo, paralelamente, promoveu o seu ingresso no país em um novo formato de lojas.

Assim, por exemplo, a receita da rede em 2001 foi de $\mathrm{R} \$ 9,2$ bilhões inferior aos $\mathrm{R} \$ 9,5$ bilhões do ano anterior, refletindo dificuldades na assimilação das redes adquiridas. Se por um lado o crescimento do Carrefour no Brasil foi acelerado por meio da estratégia de aquisições de outras redes, principalmente a partir de meados da década de 1990, quando então saiu do segmento de hipermercados para atuar no de supermercados, observa-se que essa estratégia não foi muito bem-sucedida, pois, conforme apresentado no Quadro 5, foram feitos vários spin-offs (desinvestimentos) de algumas lojas no Brasil.

\begin{tabular}{|l|l|}
\hline Data & \multicolumn{1}{|c|}{ Aquisição } \\
\hline 2001 & $\begin{array}{l}\text { O Bompreço adquiriu cinco lojas Stoc, do Carrefour, em João Pessoa, Campi- } \\
\text { na Grande, Petrolina (PE) e Teresina (PI) }\end{array}$ \\
\hline 2001 & $\begin{array}{l}\text { A rede Sonae adquiriu do Carrefour duas lojas, uma em Blumenau e outra em } \\
\text { Joinville }\end{array}$ \\
\hline 2003 & A rede EPA adquiriu cinco lojas do grupo Carrefour em Minas Gerais \\
\hline 2004 & $\begin{array}{l}\text { Os irmãos Cunha, que haviam aberto a rede de supermercados Prezunic algum } \\
\text { tempo depois de venderem as redes Rainha, Dallas e Continente ao Carrefour, } \\
\text { adquiriram do grupo francês três das antigas lojas vendidas }\end{array}$ \\
\hline 2005 & $\begin{array}{l}\text { A Prezunic adquiriu do Carrefour a loja Champion que operava em Vista } \\
\text { Alegre, no Rio de Janeiro }\end{array}$ \\
\hline
\end{tabular}

Quadro 5: Spin-offs Realizados pelo Carrefour.

Fonte: Banco de dados próprio. 
Além disso, a rede enfrentou problemas mais sérios em outras lojas, fechando várias unidades. Isso demonstra que sua estratégia de crescimento via aquisições de outras empresas não foi tão bem-sucedida como se esperava. Pode-se citar como exemplo desse insucesso estratégico:

a) o fechamento de um hipermercado carioca, na Tijuca em 2005;

b) a venda de uma loja da bandeira Champion em Vista Alegre para o Prezunic; e

c) encerramento das atividades de 13 lojas Champion no Rio de Janeiro em um único mês.

No balanço geral, a rede fechou cerca de 60 supermercados entre 2005 e 2006, encerrando o ano de 2005 com 134 lojas no país. Segundo Dambrósio e Marinelli (2007), no ano de 2006, 34 lojas que tinham a bandeira Champion foram transformadas em Carrefour-Bairro. Além disso, a área de serviços tem merecido especial atenção, sendo que os postos de gasolina, farmácias e agências de viagens já representaram, em conjunto, faturamento anual superior a $\mathrm{R} \$ 2$ bilhões. O grupo contava com 53 drogarias e 17 agências de viagens. Finalmente, o grupo estava com uma loja-piloto, funcionando 24 horas por dia, no litoral paulista.

Em abril de 2007, o Carrefour reage à perda da vice-liderança: adquiriu a rede Atacadão, que tivera receitas de $\mathrm{R} \$ 4$ bilhões no ano anterior, por cerca de $\mathrm{R} \$ 2,2$ bilhões, pretendendo não apenas retomar a vice-liderança do setor, como voltar à liderança, perdida sete anos antes. A adquirida detinha 34 hipermercados - metade deles no Estado de São Paulo. O Carrefour contava com: 109 hipermercados, 34 supermercados da cadeia CarrefourBairro e 258 lojas de desconto Dia. Segundo Dambrósio e Marinelli (2007), a compra do Atacadão foi um dos maiores investimentos feitos pelo Carrefour no mundo desde 1999.

\section{Análise da Aquisição do Atacadão pelo Carrefour}

\subsection{Fatores Mercadológicos e Estratégicos}

A rede Atacadão operava 34 hipermercados - formato dominado pelo Carrefour. Assim sendo, trata-se de uma aquisição marcadamente diferente das demais do grupo francês no Brasil - que marcaram o ingresso da rede no 
formato supermercado, ou seja, lojas de vizinhança. Dado que o Carrefour possuía expertise no formato hipermercado e já operava um volume significativo dessas lojas, a aquisição da rede Atacadão significa a possibilidade de retornar à liderança do mercado supermercadista nacional por meio de uma rede na qual esse consagrado formato passa a ter um papel ainda mais preponderante.

O fato de o Atacadão operar no formato que vem sendo informalmente denominado de "atacarejo" pode significar um atrativo adicional para a sua aquisição pelo Carrefour - por ser um nicho por ele ainda não explorado, $e$ que se constitui em uma possível forma de enfrentar a rede Sam's Club, da Wal-Mart. Além disso, dado que a rede Atacadão estava à venda há alguns anos, a compra por parte do Carrefour também pode ser considerada defensiva, pois, no caso de vir a ser adquirida por algum outro grupo, haveria a possibilidade de ingressar outro player estrangeiro no mercado brasileiro, ou de algum dos grandes concorrentes - Wal-Mart ou Pão de Açúcar - vir a adquirir essa rede, e se distanciar à frente do Carrefour.

\subsection{Fatores Políticos}

O fato de o Carrefour estar presente no país desde o ano de 1975 e de ter chegado à liderança do mercado apenas por meio da abertura de lojas permite ao grupo a realização de uma compra de maior porte, de modo a enfrentar o maior varejista mundial. Além disso, não eram esperadas reações nacionalistas, pelo fato de que metade do capital do Pão de Açúcar já estava sob controle de um grupo francês, o grupo Casino, e de que o outro grande player do mercado é o Wal-Mart - maior varejista mundial, e que fizera duas importantes aquisições no mercado brasileiro. Esses fatos implicam em que ninguém poderia dizer que o crescimento do Carrefour ao comprar a rede Atacadão poderia vir a fazer sombra a algum grupo eminentemente nacional.

\subsection{Principais Sinergias Esperadas}

Baseado na teoria sobre F\&As e na análise da aquisição, o Quadro 6 apresenta as principais sinergias esperadas com a aquisição. 


\begin{tabular}{|c|c|}
\hline Sinergia & Origem \\
\hline $\begin{array}{l}\text { Aumento das } \\
\text { receitas }\end{array}$ & $\begin{array}{l}\text { O Carrefour apresenta um aumento de receitas líquidas da ordem } \\
\text { de } \mathrm{R} \$ 4 \text { bilhões }\end{array}$ \\
\hline $\begin{array}{l}\text { Economias de } \\
\text { escala e de } \\
\text { escopo }\end{array}$ & $\begin{array}{l}\text { Mediante esse aumento de porte, o Carrefour pode ampliar a } \\
\text { pressão sobre os fornecedores }\end{array}$ \\
\hline $\begin{array}{l}\text { Melhoria de } \\
\text { eficiência produti- } \\
\text { va e da logística }\end{array}$ & $\begin{array}{l}\text { A mesma estrutura administrativa do Carrefour passa a atender } \\
\text { mais } 34 \text { hipermercados }\end{array}$ \\
\hline $\begin{array}{l}\text { Redução de } \\
\text { custos e de } \\
\text { despesas } \\
\text { operacionais }\end{array}$ & Eliminação de departamentos redundantes \\
\hline $\begin{array}{l}\text { Aumento de } \\
\text { market share }\end{array}$ & $\begin{array}{l}\text { O Carrefour amplia sua participação no mercado brasileiro, } \\
\text { passando da terceira posição para a primeira posição no ranking }\end{array}$ \\
\hline $\begin{array}{l}\text { Possibilidades de } \\
\text { melhorias na } \\
\text { qualidade }\end{array}$ & $\begin{array}{l}\text { O aumento do volume de vendas permite investimentos em quali- } \\
\text { dade dos sistemas e em treinamento de pessoal }\end{array}$ \\
\hline $\begin{array}{l}\text { Melhoria da } \\
\text { eficiência } \\
\text { gerencial }\end{array}$ & $\begin{array}{l}\text { A rede adquirida opera apenas no formato hipermercado - no qual } \\
\text { o Carrefour detém reconhecida expertise }\end{array}$ \\
\hline $\begin{array}{l}\text { Sinergias de } \\
\text { monopólio }\end{array}$ & $\begin{array}{l}\text { O aumento da receita e a presença em mais } 34 \text { hipermercados } \\
\text { permitem a ampliação do peso das marcas próprias do Carrefour } \\
\text { no país }\end{array}$ \\
\hline $\begin{array}{l}\text { Economias } \\
\text { financeiras }\end{array}$ & $\begin{array}{l}\text { Melhor estrutura de capital, maior capacidade de alavancagem } \\
\text { com menores custos de endividamento }\end{array}$ \\
\hline $\begin{array}{l}\text { Ingresso em um } \\
\text { novo formato }\end{array}$ & $\begin{array}{l}\text { O Atacadão pode ser encarado como um verdadeiro fenômeno, } \\
\text { tendo até merecido a denominação de "atacarejo"; dessa forma, a } \\
\text { aquisição representa a compra de um valioso ativo, inclusive com } \\
\text { possibilidades reais de ser introduzido em novos países }\end{array}$ \\
\hline
\end{tabular}

Quadro 6: Principais Sinergias da Aquisição.

Fonte: Elaborado pelos autores. 
Fusões e Aquisições no Varejo Alimentar: uma análise das estratégias de entrada e de crescimento do Carrefour e...

\subsection{Dificuldades da Aquisição}

As principais dificuldades esperadas com a aquisição seriam:

a) possiveis choques de culturas corporativas das empresas envolvidas;

b) divergências e incompatibilidades de estilos de gestão de empresas com focos de atuação distintos; $e$

c) desmotivação dos funcionários diante do risco de dispensa. Além dessas dificuldades, a aquisição deverá passar pelo crivo do SBDC.

\subsection{Vantagens e Desvantagens para os Stakeholders da rede Atacadão}

\begin{tabular}{|c|c|c|}
\hline Stakeholder & Vantagens & Desvantagens \\
\hline Funcionários & $\begin{array}{l}\text { - passam a ser funcionários de } \\
\text { uma empresa de maior porte, com } \\
\text { maiores oportunidades de cresci- } \\
\text { mento na carreira }\end{array}$ & $\begin{array}{l}\text { - riscos de dispensas devido ao } \\
\text { enxugamento do quadro funcional } \\
\text { no futuro, com a eliminação de de- } \\
\text { partamentos redundantes }\end{array}$ \\
\hline Proprietários & $\begin{array}{l}\text { - prêmio recebido pela venda } \\
\text { - se retiram do negócio realizan- } \\
\text { do os lucros de muitos anos de } \\
\text { investimentos }\end{array}$ & $\begin{array}{l}\text { - deixam de estar presentes nas em- } \\
\text { presas que fundaram e nos setores em } \\
\text { que já atuavam. Desse modo, perdem } \\
\text { as oportunidades de acompanhar o } \\
\text { crescimento da economia do país }\end{array}$ \\
\hline Fornecedores & $\begin{array}{l}\text { - possibilidade de passarem a for- } \\
\text { necer a toda a rede Carrefour }\end{array}$ & $\begin{array}{l}\text { - menor poder de barganha frente } \\
\text { ao maior porte do Carrefour }\end{array}$ \\
\hline Consumidores & $\begin{array}{l}\text { - aumento da competição no se- } \\
\text { tor, em função de ser um campo } \\
\text { de atuação global, e pelo fato de } \\
\text { estar sendo disputado } \\
\text { acirradamente pelos dois maiores } \\
\text { varejistas mundiais }\end{array}$ & $\begin{array}{l}\text { - diminuição do número de partici- } \\
\text { pantes do setor }\end{array}$ \\
\hline Concorrentes & $\begin{array}{l}\text { - afirmou-se que a compra do } \\
\text { Atacadão teria tido um custo mui- } \\
\text { to elevado, o que poderia com- } \\
\text { prometer os índices financeiros do } \\
\text { Carrefour }\end{array}$ & $\begin{array}{l}\text { - competição desigual } \\
\text { - menor poder de barganha junto a } \\
\text { fornecedores, credores e governo } \\
\text { - maior esforço de marketing (maio- } \\
\text { res gastos) para manter/ampliar par- } \\
\text { ticipação de mercado }\end{array}$ \\
\hline Economia/País & $\begin{array}{l}\text { - importante ingresso de divisas } \\
\text { por parte do Carrefour para liqui- } \\
\text { dar a aquisição }\end{array}$ & $\begin{array}{l}\text { - concentração no varejo alimentar } \\
\text { - venda de mais um grupo nacional } \\
\text { atuante no setor }\end{array}$ \\
\hline
\end{tabular}

Quadro 7: Vantagens e desvantagens para os stakeholders da rede Atacadão.

Fonte: Elaborado pelos autores. 


\section{Considerações Finais}

Neste artigo fez-se uma análise das estratégias de entrada, da trajetória de crescimento das redes Wal-Mart e Carrefour, bem como da aquisição da rede Atacadão pelo Carrefour. As duas empresas apresentaram estratégias de entrada distintas no mercado brasileiro. A primeira ingressou tardiamente no Brasil, 20 anos após a segunda, somente em 1995; mas utilizou-se de uma aliança estratégica bem-sucedida com uma empresa brasileira (jointventure com a Lojas Americanas), a qual possibilitou a rápida assimilação da cultura e dos padrões de negócio do mercado local. O Carrefour adotou uma estratégia de entrada do tipo greenfield, quando do seu ingresso no Brasil em 1975, com a implantação de hipermercados - modelo de negócios no qual a empresa detém expertise mundialmente reconhecida, tendo sido pioneira com esse modelo na Europa. Com a elevada inflação, a rede enfrentou notável crescimento, apenas mediante a abertura de novos hipermercados; e passou a realizar aquisições apenas na segunda metade dos anos 90, para ingressar no formato dos supermercados, além de aproveitar oportunidades ocasionais na área de hipermercados, como a rede Eldorado.

Ressalta-se que a aliança estratégia entre a Wal-Mart e a Lojas Americanas ao atingir seus objetivos foi desfeita. Enquanto durou a parceria, a primeira ganhou importantes conhecimentos sobre o mercado brasileiro. A segunda não temia passar isso ao parceiro, pois vendera os seus 23 supermercados (curiosamente ao próprio Carrefour). Em troca ela ganhou acesso à tecnologia dos centros de distribuição da Wal-Mart, o que lhe permitiu passar a operar com muito maior agilidade e eficiência operacional.

Conforme discutido anteriormente, a entrada desses dois players de atuação mundial provocou mudanças estruturais no setor, no sentido de implantar ações de neutralizar a concorrência, criação de vantagens competitivas, redefinição de mercados e mudanças de controle acionário (ROCHA; DIB, 2002). Minadeo (2008) apresenta a visão de vários autores, segundo a qual a internacionalização do varejo foi mais tardia do que a da indústria, $e$ exemplifica com a Ikea - maior varejista mundial de móveis, que jamais teria chegado ao posto de maior varejista mundial de móveis se restrita ao seu mercado original.

No que se refere ao crescimento das duas empresas no mercado brasileiro, ao contrário, das formas de ingresso, pode-se traçar um paralelo nas 
estratégias adotadas. Ambas priorizaram o crescimento orgânico nos anos iniciais (Wal-Mart nos dez e Carrefour nos 20 primeiros anos) - período em que ambas conheceram as peculiaridades do mercado e do comportamento do consumidor brasileiro. Após isso, continuaram com o crescimento orgânico, mas passaram a adquirir redes locais. Nesta segunda etapa, o crescimento das duas empresas foi maior com aquisições do que com a abertura de novas lojas.

Pode-se dizer que a Wal-Mart teve um atalho com a parceria estratégica com a Lojas Americanas e fez aquisições mais bem-sucedidas: comprou duas redes de supermercados regionalmente concentradas (um na região Sul $e$ outra no Nordeste), ambas formadas por grupos estrangeiros que haviam consolidado redes regionais mediante aquisições e estavam implantando um processo de profissionalização nas adquiridas, que eram empresas familiares. Finalmente, a Wal-Mart se beneficiou da oportunidade dessas redes estrangeiras estarem fazendo spin-offs de seus ativos internacionais devido a problemas financeiros - pagando preços relativamente menores em função das notórias necessidades imediatas de caixa dos grupos vendedores.

No que se refere ao Carrefour, durante alguns anos todo o seu ingresso em lojas do tipo supermercado mediante aquisições. Em 1999, a rede fundiu-se mundialmente com o grupo Promodès. Vários autores apontam essa união como defensiva contra um possível ingresso do Wal-Mart na França, ao criar o segundo maior varejista do mundo. A partir desse momento, aparentemente sem uma estratégia de assimilação das aquisições realizadas, o desempenho das adquiridas caiu fortemente, na tentativa de ingressar no formato de lojas de vizinhança. Foram feitos investimentos para transformálas no padrão com a bandeira Champion, porém sem obter os resultados almejados. Até o reposicionamento dessa estratégia, para transformar essas lojas em Carrefour Bairro, foram feitos vários spin-offs, alguns dos quais para os proprietários originais, além do fechamento de várias unidades. Isso mostra que a estratégia de crescimento adotada passou por alguns problemas na assimilação das empresas adquiridas - além de se incorrer em vários prejuízos.

Após ações como a implantação da bandeira Carrefour-Bairro e o incremento de novos formatos de negócio, como postos de gasolina e drogarias, o Carrefour deu mostras de haver finalmente consolidado as aquisições realizadas, estando preparado para uma resposta estratégica à perda da liderança em receitas no ano 2000 ao Pão de Açúcar e da vice-liderança em 2006 ao Wal-Mart. Assim, a aquisição da rede Atacadão pode ser vista como 
estratégica para a retomada da liderança no segmento e para defender-se de seus maiores concorrentes no mercado brasileiro ou do possível ingresso de algum novo player mediante a compra desse interessante ativo. A aquisição pode desempenhar um importante papel e dar a volta por cima em sua trajetória de aquisições no mercado brasileiro, coroando uma bem-sucedida série de inovações já iniciada no ano anterior.

\title{
Grocery Retail's Merger and Acquisitions Brazilian Case: entrance and growth's strategies analysis of Carrefour and Wal-Mart
}

\begin{abstract}
In 2006, Carrefour in Brazil was exceeded by Wal-Mart, assuming the third position in supermarkets' ranking. War-Mart entered Brazilian market in 1995, facing innumerable problems in its first years. However, later undertook a vigorous program of growth for the opening of new stores, and for the acquisition of some national groups. Carrefour arrived in Brazilian market in 1975 , and reached the leadership of ranking in 1990, only through a program of opening new stores, in the hypermarket format. In this decade, it initiated a process, acquiring diverse local groups, to enter the neighborhood retail. However, this strategy had failed. After the announcement of the loss of the second position to Wal-Mart, Carrefour announces the acquisition of Atacadão, aspiring to retake the leadership. This article aims analyze the entrance strategies, the trajectory of growth of the two companies, as well as the acquisition of Atacadão by Carrefour. This acquisition for Carrefour was strategic to retake leadership in the segment and to defend itself to new competitors.
\end{abstract}

Key-words: Entrance Strategy. Growth Strategy. Mergers and Acquisitions. Retail Industry. Carrefour. Wal-Mart. 


\section{Referências}

ABRAS - ASSOCIAÇÃO BRASILEIRA DE SUPERMERCADOS. 40 anos de Supermercados no Brasil. São Paulo: ABRAS, 1993. 186p.

ALMEIDA, V. M. C. Fatores antecedentes da escolha do modo de entrada em mercados extra-regionais e conseqüências no desempenho: um modelo contingencial de expansão extra-regional do varejo. 2005. 298 f. Tese (Doutorado em Administração) - Instituto COPPEAD de Administração, Universidade Federal do Rio de Janeiro, Rio de Janeiro.

ANDRADE, G.; MITCHELL, M.; STAFFORD, E. New evidence and perspectives on mergers. Journal of Economic Perspectives, v. 15, n. 1, p. 103-120, 2001.

BARNEY, J. Firm resources and sustained competitive advantage. Journal of Management Studies, v. 17, n. 1, p. 99-120, 1991.

BURT, S.; DAWSON, J.; SPARKS, L. Failure in international retailing: research propositions. The International Review of Retail, Distribution and Consumer Research, v. 13, n. 4, p. 355-373, 2003.

CÂMARA, G. A. N. Fusões e aquisições: análise do desempenho, da performance e da competitividade: estudo de caso do sistema Usiminas. 2007. 123 f. Dissertação (Mestrado em Administração). Centro de Pós-Graduação e Pesquisas em Administração, Universidade Federal de Minas Gerais, Belo Horizonte.

CHANDLER, A. D. The visible hand. Cambridge, Massachusetts: The Belknap Press of Harvard University Press, 1997. 608 p.

CHATTERJEE, S. Types of synergy and economic value: the impact of acquisitions on merging and rival firms. Strategic Management Journal, v. 7, n. 2, p. 119-139, 1986.

CHRISTOPHER, M. A logística do marketing. São Paulo: Futura, 1999.

COASE, R. H. The nature of the firm. Economica, v. 4, n. 16, p. 386-405, 1937. 
COLLA, E. The outlook for european grocery retailing: competition and format development. The International Review of Retail, Distribution and Consumer Research, v. 14, n. 1, p. 47-69, 2004.

COSTA, A. J. D. Wal-Mart e sua estratégia para o varejo norte-americano e internacional. História Econômica \& História de Empresas. ABPHE, v. 8, p. 2, p. 145-168, 2005. 2006. 204 p.

Sucessão e sucesso nas empresas familiares. Curitiba: Juruá,

DAMBRÓSIO, D.; MARINELLI, L. Carrefour prepara novas investidas, pós-atacadão, 2007. Disponível em: <http//:www.valorOnline.com.br $>$. Acesso em: 25 jun. 2009.

DAWSON, J. Strategy and opportunism in european retail internationalization. British Journal of Management, v. 12, n. 3, p. 253-266, 2001.

FOX, M. Market power in music retailing: the case of Wal-Mart. Popular Music and Society, v. 28, n. 4, p. 501-519, 2005.

GARCEZ, M. P. A seleção das estratégias de crescimento e diversificação: um estudo de casos na indústria petroquímica. In: ENCONTRO NACIONAL DE PROGRAMAS DE PÓS-GRADUAÇÃO EM ADMINISTRAÇÃO, 30. 2006, Salvador (BA). Anais Eletrônicos... Rio de Janeiro: ANPAD, 2006. (1 CD$\mathrm{ROM})$.

GHEMAWAT, P. A estratégia e o cenário dos negócios. Bookman: Porto Alegre, 2000.

GONÇALVES, R. et al. A nova economia internacional: uma perspectiva brasileira. Rio de Janeiro: Campus, 1998.

HEITMANN, F. C. T. Centro de distribuição como fator de vantagem comparativa através de um estudo de caso. 2002. 119 f. Dissertação (Mestrado em Administração). Universidade Estácio de Sá - UNESA, Rio de Janeiro.

HIRSCHEY, M. Merger, buyouts and fakeouts. The American Economic Review, v. 76, n. 2, p. 317-321, 1986. 
HOLMSTRON, B.; KAPLAN, S. N. Corporate governance and merger activity in the United States: making sense of the 1980s e 1990s. Journal of Economic Perspectives, v. 15, n. 2, p. 121-144, 2001.

JOVANOVIC, B.; ROUSSEAU, P. The Q-theory of mergers. American Economic Review, v. 92, n. 3, p. 198-204, 2002.

KATZ, J. P.; SIMANEK, A.; TOWNSEND, J. B. Corporate mergers and acquisitions: one more wave to consider. Business Horizons, v. 40, n. 1, p. 32-40, 1997.

KPMG. Pesquisa de fusões e aquisições: espelho das transações realizadas no Brasil, 2006. $4^{\circ}$ trimestre e acumulado. São Paulo: KPMG. Disponível em: $<$ http://www.kpmg.com.br/publicacoes/fusoes_aquisicoes/2006/ fusoes_2006_4trim.pdf>. Acesso em: 6 jul. 2009.

LAKATOS, E. M.; MARCONI, M. A. Metodologia científica. São Paulo: Atlas, $1991.288 \mathrm{p}$.

LEMES Jr., A. B.; RIGO, C. M.; CHEROBIM, A. P. M. S. Administração financeira: princípios, fundamentos e práticas brasileiras. Rio de Janeiro, 2002. 698 p.

MARTINS, G. A. Estudo de caso: uma estratégia de pesquisa. São Paulo: Atlas, 2006. 102 p.

MINADEO, R. Fusões e aquisições no varejo alimentar. s/d. Disponível em: <http://www.varejista.com.br>. Acesso em: 20 out. 2009

Internacionalização do varejo: o caso IKEA. Revista Alcance, v. 15, n. 3, set.-dez. 2008, p. 379-397.

MINTZBERG, H.; WATERS, J. Of Strategies, deliberate and emergent.

Strategic Management Journal, v. 6, n. 2, p. 257-272, 1985.

OLIVEIRA, L. M. J. Trajetória de crescimento e traços organizacionais do grupo Brasmotor. 2006. 406 p. Dissertação (Mestrado em Administração). Instituto COPPEAD de Administração. Universidade Federal do Rio de Janeiro, Rio de Janeiro.

PENROSE, E. T. The theory of the growth of the firm. Great Britain: Oxford Basil Blackwell, 1959. 
PINTO JÚNIOR, H.; IOOTTY, M. Avaliando os impactos microeconômicos das fusões e aquisições nas indústrias de energia no mundo: uma análise para a década de 90. Revista de Economia Política, v. 25, n. 4, 2005.

RASMUSSEN, U. W. Aquisições, fusões e incorporações empresariais. São Paulo: Aduaneiras, 1989.

ROCHA, A.; DIB, L. A. The entry of Wal-Mart in Brazil and the competitive responses of multinational and domestic firms. International Journal of Retail \& Distribution Management, v. 30, n. 1, p. 61-73, 2002.

ROSS, S. A.; WESTERFIELD, R. W.; JAFFE, J. F. Administração financeira: corporate finance. São Paulo: Atlas, 2002. 776 p.

SCHERER, F; ROSS, D. Industrial market structure and economic performance. $3^{\text {th }}$ ed. Boston: Houghton Mifflin Company, 1990.

SHLEIFER, A.; VISHNY, R. W. Stock market driven acquisitions. Journal of Financial Economics, v. 70, n. 2, p. 295-311, 2003.

SINGH, H.; MONTGOMERY, C. A. Corporate acquisitions strategies and economic performance. Strategic Management Journal, v. 8, n. 4, p. 377386, 1987.

SILVERSTEIN, M. J.; FISKE, N. Luxo para as massas. Harvard Business Review. São Paulo; Edição Brasileira, 2003.

SMITH, A. A riqueza das nações. Investigação sobre sua natureza e suas causas. São Paulo: Abril Cultural, Livro I, Os Economistas, 1996.

STARBUCK, W. Organizational growth and development. England: PenguinBooks, 1965.

STERNQUIST, B. International retailing. New York: Fairchild Publications, 1998.

STERNQUIST, B. International expansion of US retailers. International Journal of Retail \& Distribution Management, v. 25, n. 8, 1997 , p. 262268.

SUEN, A. S.; KIMURA, H. Fusões e aquisições como estratégia de entrada (entre mode) no mercado brasileiro. Caderno de Pesquisas em Administração, São Paulo, v. 2, n. 5, p. 53-60, 1997. 
Fusões e Aquisições no Varejo Alimentar: uma análise das estratégias de entrada e de crescimento do Carrefour e...

VIEIRA, F. H. C. Análise da trajetória de crescimento do grupo Gerdau. 2007. 356 f. Dissertação (Mestrado em Administração). Instituto COPPEAD de Administração. Universidade Federal do Rio de Janeiro, Rio de Janeiro.

WALTON, S.; HUEY, J. Made in America. Rio de Janeiro: Campus, 1993.

WESTON, J. F.; BRIGHAM, E. F. Fundamentos da administração financeira. 10. ed. São Paulo: Makron Books, 2000. 1030 p.

WHITEHEAD, M. B. Internationalization of retailing: developing new perspectives. European Journal of Marketing, Bradford, v. 26, n. 8/9, p. 74-79, 1992.

WORTMANN, M. Aldi and the german model: structural change in german grocery retailing and the success of grocery discounter. Competition \& Change, v. 8, n. 4, p. 425-441, 2004.

WRIGHT, P.; KROLL, M. J.; PARNELL, J. Administração estratégica: conceitos. São Paulo: Atlas, 2000. 